\title{
Bütünleşik Bulanık AHP-VIKOR Yaklaşımıyla Demiryolu Yük Taşımacılığı Etkinliklerinin Değerlendirilmesi
}

\section{Evaluation of Railway Freight Transportation Activities with Integrated Fuzzy AHP-VIKOR Approach}

\section{Dr. Öğr. Üyesi Gökçe Candan ${ }^{1}$}

Başvuru Tarihi: 13.10.2018

Kabul Tarihi: 09.04.2019

Öz

Demiryolu yük taşımacıllğı birçok avantajı sayesinde uzun yıllardır lojistik hizmetlerin önemli bir parçası olmayı sürdürmekte, sabit ulaştırma süreleri, güvenlik, izlenebilirlik gibi özellikleriyle diğer ulaştırma yöntemlerinin yerine tercih edilmektedir. Bu çalışmada sekiz adet OECD üyesi ülkenin demiryolu yük taşımacılı̆̆ı etkinlikleri değerlendirilmiştir. Değerlendirme kriterleri olarak, firma sayısı, hat uzunluğu (km), taşıma miktarı (ton), bakım giderleri (Euro) ve altyapı yatırımları ele alınmıştır. Bu kriterlere ait ağırlıklar bulanık AHP yöntemi ile elde edilmiş ve ülkelerin etkinlik performanslarının stralaması gerçekleştirmek için ise VIKOR yöntemi kullanılmıştır. Çalışmada kullanılan bulanık AHP ve VIKOR bütünleşik yöntemi, çeşitli etkinlik ve performans değerlendirmeleri için farklı sektörlerde de uygulanabilecek esnek bir yöntemdir. Elde edilen sonuçlara bakıldiğında; kriterlerin önem dereceleri sırasıyla taşıma miktarı (K3), hat uzunluğu (K2), altyapı yatırımları (K5), bakım giderleri (K4), firma sayısı (K1) şeklinde olup, ülkelerin performans sıralaması Polonya- İsveç- Avusturya- Çek Cumhuriyeti- TürkiyeMacaristan- Finlandiya- Slovakya şeklinde olduğu görülmektedir.

Anahtar Kelimeler: Demiryolu yük taşımacılığı, Bulanık AHP, VIKOR

\begin{abstract}
Thanks to its many advantages, railway freight transportation has been an important part of logistics services for many years, and it is preferred to replace other transportation methods with its fixed transportation times, safety and traceability. In this study, rail freight transport activities of eight OECD member countries were evaluated. As the evaluation criteria, number of firms, line length (km), amount of transport (ton), maintenance costs (Euro) and infrastructure investments are discussed. The weights of these criteria were obtained by fuzzy AHP method and the VIKOR
\end{abstract}

${ }^{1}$ Sakarya Üniversitesi Siyasal Bilgiler Fakültesi, gcandan@sakarya.edu.tr, ORCID: 0000-0002-5966-0009 
method was used in order to perform the performance of the countries. The fuzzy AHP and VIKOR integrated method is a flexible method which can be applied in different sectors for various efficiency and performance evaluations. Looking at the results; weights of criteria respectively; amount of transport (K3), line length (K2), infrastructure investments (K5), maintenance costs (K4) number of firms (K1) and in the form of country performance ranking Poland-SwedenAustria-Czech Republic-Turkey Hungary - Finland - Slovakia.

Keywords: Railway Freight Transportation, Fuzzy AHP, VIKOR

\section{Giriş}

Tedarik zinciri yönetiminin önemli bir bileşeni olan yük taşımacıllğı, lojistik performans göstergesinin de temel parçasıdır. Yük taşımacilığında, karayolu, denizyolu, havayolu ve demiryolu gibi taşımacılık seçenekleri bulunmaktadır. Bu seçenekleri tek türlü (tek modlu), kombine olarak çok modlu (multimodal) veya modlar arası (intermodal) kullanmak da mümkündür. Fakat bunların içerisinde demiryolu taşımacılığının birçok avantajı söz konusudur.

Demiryolu taşımacilığı yüksek hacimli ürünlerin uzun mesafelere düşük maliyetlerle taşınmasını sağlayabilmektedir. Güvenilir, takip edilebilir ve müşteri memnuniyetini bu yönüyle artırabilir hizmetler sunmaktadır. Ulaştırma süreleri değişken değil, sabittir. Bu yönleriyle demiryolu yük taşımacilığ ekonomik büyümeyi artırırken, çevreye verdiği zarar da diğer taşımacılık yöntemlerine göre düşük olduğundan, ülkeler demiryolu taşımacılığı yatırımlarına devam etmektedirler. Yapılan yatırımlar, demiryolu hatlarının bakımı, yenilenmesi, yeni hatların oluşturulması, vagon ve lokomotiflerin bakımı ve satın almaları, personel işe alımları, hizmet binaları yenilemeleri, teçhizat yenilemeleri şeklinde sayılabilir. $\mathrm{Bu}$ yatırımların maliyetleri ise oldukça yüksektir.

Vagonların yük kapasiteleri de taşıma hacmiyle doğrudan bağlantılıdır. Gelişmiş ülkelerde demiryolu yük taşımacıllğı etkin bir şekilde kullanılmaktadır ve bazı üretim işletmelerinde depo kapılarına kadar ray döşeli olduğu bilinmektedir. Yine gelişmiş ülkelerde limanlar ve sanayi bölgeleri demiryolu ağıyla birbirlerine bağlıdır. Bu etkin yük taşımacilığı sistemini daha da verimli kılmak için literatürde birçok çalışma ile karşlaş̧maktayız. Bunlardan birçoğu çok kriterli karar verme (ÇKKV) yöntemleriyle gerçekleştirilmiş olup performans değerlendirmesi ve stratejik karar destek modeli oluşturulması şeklindedir. Demiryolu yük taşımacılığı ile ilgili literatürdeki bazı çalışmalar şu şekildedir: Veskovic vd. (2008) Delphi, SWARA ve MABAC yöntemlerini birlikte kullanarak Bosna-Hersek'te demiryolu taşımacilı̆̆ yönetimi değerlendirmesi gerçekleş̧irmişlerdir. Bojovic ve Milenkovic (2008), AHP yöntemi ile ulaşım taleplerine cevap verebilmek için en iyi demiryolu filosu belirlemeyi hedeflemişlerdir. Nyström ve Söderholm (2008) çalışmalarında demiryolu altyapı yönetiminde 8 ayrı kriter üzerinden bakım faaliyeti biçimi seçimi için AHP yöntemini kullanmışlardır. Longo vd (2009) İtalya 
Turin'de demiryolu taşımacilığı alanında stratejik karar destek yöntemi geliştirmeyi hedeflemişlerdir. Ele aldıkları değerlendirme kriterleri, maliyetler, ulaşım verimliliğ̈i, çevresel etkiler, uygulama açlarıdır ve hem AHP hem de ANP ile değerlendirme yapmışlar ve sonuçları karşılaştırmışlardır. Gürsoy (2010), multimodal ulaşım modu seçimi için AHP temelli yeni bir karar destek modeli oluşturmuşlardır. Bunu gerçekleştirirken ele aldığı kriterler ise nakliye mesafesi, zaman, güvenlik, erişilebilirliktir. Nuhodzic vd. (2010), demiryolu sektöründe yer alan bir şirketinin pazarlama stratejileri ile ilgili kampanya seçimi bulanık AHP yöntemi ile ele alınmıştır. Çekerol ve Nalçakan (2011) ridge regresyon analizi ile Türkiye'de demiryolu taşımacılığına etki eden faktörleri belirlemişlerdir. Çalışmalarında bağımlı ve bağımsız değişkenler belirlemişlerdir. Bunlardan bağımlı olarak demiryolu yurtiçi yük taşıma talebi belirlenmişken, bağımsız değişkenler ise; yurtiçinde karayolu ile taşınan toplam yük miktarı, demiryoluna yapılan toplam yatırım miktarı, TCDD limanlarında elleçlenen toplam yük miktarı, kişi başına gayri safi yurtiçi hâsıla, demiryolu enerji tüketim gideri, demiryolu yük taşıma giderleridir. Gürol vd. (2015), zaman serileri kullanarak Türkiye'de demiryolu ile yük taşıma miktarı belirlemesi problemini ele almışlardır. Tadic vd. (2015) bulanık AHP ve VIKOR yöntemleriyle üç ayrı lojistik model senaryosunu 9 ayrı kriter üzerinden değerlendirerek, bir şehrin lojistik sisteminin seçimini gerçekleştirmişlerdir. Hajiagha vd. (2016) Tahran şehir metrosunda gecikmelere neden olan etkenleri VIKOR yöntemi ile sıralamışlardır. Ranjan vd (2016), Hindistan'da demiryolu hatlarının performans değerlendirmesi için DEMATEL ve VIKOR metodlarını kullanmışlardır. Ele aldıkları kriterler, rota uzunluğu, lokomotif sayısı, taşınan yolcu sayısı, büyük istasyon sayısı, yapılan kaza sayısı, yaralanan kişi sayısı, işletme maliyetleri ve harcamalar şeklindedir. Ahi ve Yıldız (2017) çalışmalarında, Türkiye'de demiryolu lojistiğinin analizini gerçekleştirmek için ele aldıkları 250 parametre ile SCOR modeli kullanmışlardır. Taherkhani ve Esfahani (2017), demiryolu rayları için malzeme seçim problemini SWARA ve VIKOR yöntemleriyle ele almışlardır. Bu iki ayrı metotla elde ettikleri sonuçları kıyaslamışlardır.

Literatürde, demiryolu yük taşımacillğı performansını çok kriterli karar verme tekniklerinin yanı sıra çeşitli yöneylem araştırması ve diğer sayısal yöntemlerle ölçen çalışmalara da rastlamaktayız. Bunlar ele aldıkları performans kriterlerine göre değerlendirildiğinde benzer özellikler göstermektedir. Bu çalışmalardan başlıcaları; Yu ve Lin (2008) çalışmalarında veri zarflama analizi yöntemiyle dünya genelinde ülkelere ait demiryolu etkinliğini ölçmüşlerdir. Burada kullandıkları kriterler; demiryollarında çalışan personel sayısı, hat uzunluğu, taşınan yük (ton-km), taşınan yolcu $(\mathrm{km})$ şeklindedir. Wanke vd. (2018) çalışmalarında demiryolu performansına etki eden kriterleri belirlerken ağ veri zarflama analizi kullanmışlardır. Asya ülkeleri üzerinde gerçekleştirdikleri çalışmada ele alınan performans kriterleri enerji, çalışan sayısı, tren yük kapasitesi, taşınan yük, taşınan yolcu, kaza sayısı, gelir şeklindedir. Zahurul Islam (2018) çalışmasında, Avrupa'da Ekonomik tasarruf durumunda sürdürülebilir ulaştırma sistemi geliştirmenin önündeki engelleri kaldırmak için ulaştırma altyapısındaki yatırımları ve demiryolu ihtiyacını değerlendirmiş̧tir. Bunun için, kullanılan demiryolu hatlarının uzunluğuna bağlı olarak sekiz AB ülkesi seçilmiştir ve bunlar; Fransa, Almanya, İtalya, Romanya, İspanya, İsveç, İngiltere ve Polonya şeklindedir. Hilmola (2007), Avrupa'daki Finlandiya, İsveç, Polonya, Letonya, Litvanya ve Estonya ülkelerinde 1980-2003 yılları arasında 
demiryolu yük taşımacılığı verimliliğinin analizini gerçekleştirmiştir. Değerlendirme için ele alınan kriterler ise; yük (ton- $\mathrm{km}$ ), yolcu sayısı $(\mathrm{km})$, yük vagonu sayısı, yolcu vagonu sayısı, yük vagonu ağırlığı ve yolcu vagonu ağıllığı şeklindedir. Wiegmans vd. (2018) çalışmalarında demiryolu yük taşımacıllğı ağ etkinliğini dünya genelinde analiz etmişlerdir. Elde ettikleri sonuçlara göre, Avrupa'da demiryolu yük taşımacılığında daha fazla verimlilik için şirketlerin teşvik edilmesi gerektiğini ve bunun için Avrupa genelinde bir verimlilik politikası geliştirmek gerektiğini önermişlerdir.

Ayrıca literatürdeki çalışmalarda demiryolu gibi; havayolu, denizyolu, karayolu gibi çeşitli yük taşıma etkinliklerinin performansları ölçülürken kullanılan kriteler de birbirine benzerlik göstermektedir. Bu kriterler; çalışan sayısı, taşınan yük (ton-km), işletme maliyetleri, seyahat planına uyma oranı, sürücü sayısı, yakıt maliyetleri, taşınan yolcu sayısı, hat uzunluğu, kaza sayısı şeklindedir (Sheth vd. (2007), Yu (2008), Chiou vd. (2012), Liu (2016), Yu vd. (2016).

Literatürde son yıllarda yapılan çalı̧malarda demiryolu yük taşımacılığı planlama ve çizelgeleme problemlerinin çözüldüğünü de gözlemlemekteyiz (Cacchiani vd 2010, Anghinolfi vd. 2011, Yang vd. 2011, Yaghini ve Akhavan 2012, Zhang ve Zhang 2019).

Bu çalışmada OECD üyesi 7 ülke için 8 kriter üzerinden demiryolu yük taşımacılığı etkinlikleri değerlendirilmiştir. Kriterlere ait ağırlıklar bulanık Analitik Hiyerarşi (AHP) yöntemiyle elde edilmiştir ve etkinlik sıralamaları Vise Kriterijumska Optimizacija I Kompromisno Resenje (VIKOR) yöntemiyle yapılmıştır.

Literatürde bu iki yöntemi bütünleşik bir şekilde kullanarak demiryolu yük taşımacıllı̆̆ değerlendirmesi gerçekleştiren bir çalışmaya rastlanmamaktadır. Ayrıca çalışmanın, ele alınan değerlendirme kriterleri açısından da literatüre yeni bir bakış açısı sağlayacağı düşünülmektedir.

\section{Bulanık AHP Metodu}

Analitik hiyerarşi Prosesi (AHP) 1977'de Thomas L. Saaty tarafindan kompleks problemlerin çözümünde kullanılmak için geliştirilmiş bir ÇKKV tekniğidir. Bu yöntem ile, karar vermek için sorumlu uzman kişiler tarafından probleme ait amaçlar ortaya konulur ve sonra amaçlara ulaşmak için değerlendirilmesi gereken kriterler ve alternatiflerden oluşan hiyerarşik bir yapı oluşturulur. Bu kriterler ve amaçlar önem derecelerine göre birbirleriyle kıyaslanırlar ve ikili karşılaştırma matrisleri elde edilir. Matrislerin tutarlılıkları değerlendirilir ve alternatifler önem derecelerine göre siralanırlar.

Gerçek hayatta kararlar alırken ortaya çıkacak kararsızlık ve belirsizlik durumlarının modellenebilmesi için AHP yöntemi bulanık mantık teorisiyle bütünleştirilip, bulanık AHP yöntemi ortaya konulmuştur. $\mathrm{Bu}$ yöntemde kriterlerin önem dereceleri bir değerler aralığı şeklinde ortaya konulur. Literatürde üyelik fonksiyonlarının durumuna göre (üçgensel, yamuk vb.) çeşitli bulanık AHP uygulamaları mevcuttur (Buckley 1985, Chang 1996, Laarhoven ve 
Pedrycz 1983). Bu çalışmada Buckley 1985 tarafından önerilen bulanık AHP metodu kullanılmıştır. $\mathrm{Bu}$ yöntemde kullanılan dilsel değişkenler ve bulanık ölçek Tablo 1'de görülmektedir.

Tablo 1. Dilsel değişkenler ve üçgensel bulanık sayılar

\begin{tabular}{lc}
\hline Dilsel Değişkenler & $\begin{array}{c}\text { Bulanık } \\
\text { Ölçek }\end{array}$ \\
\hline Eşit Derecede Önemli & $(1,1,1)$ \\
Orta Derecede Önemli & $(2,3,4)$ \\
Kuvvetli Derecede Önemli & $(4,5,6)$ \\
Çok Kuvvetli Derecede Önemli & $(6,7,8)$ \\
Mutlak Derecede Önemli & $(9,9,9)$ \\
\hline
\end{tabular}

Yöntemin aşamaları şu şekildedir:

1. Adım: Kriterler arasında ikili kıyaslamalar yapılır ve ikili karşılaştırma matrisleri oluşturulur. Buna göre hangi kriterin daha önemli olduğu sorgulanarak, karşıllk gelen dilsel ifadeler belirlenir.

$\widetilde{D}=\left[\begin{array}{cccccc}1 & \tilde{a}_{12} & \tilde{a}_{13} & \ldots & \tilde{a}_{1 n} \\ \tilde{a}_{21} & 1 & \tilde{a}_{23} & \ldots & \tilde{a}_{2 n} \\ \vdots & \vdots & \vdots & & \ddots & \vdots \\ \tilde{a}_{n 1} & \tilde{a}_{n 2} & \tilde{a}_{n 3} & \ldots & 1\end{array}\right]$

2. Adım: Bu adımda aşağıdaki eşitlik ile bulanık geometrik ortalama belirlenir.

$$
\tilde{r}_{i}=\left(\tilde{a}_{i 1} \otimes \tilde{a}_{i 2} \otimes \ldots \otimes \tilde{a}_{i n}\right)^{1 / n}
$$

3. Adım: Aşağıdaki eşitlik kullanılarak her bir kriterin bulanık ağırlığı hesaplanır. Bunun için öncelikle her bir $\tilde{r}_{i}$ 'e ait vektör toplamı elde edilir. Bu toplamın tersi alınır ve her bir $\tilde{r}_{i}$ ile çarpılır.

$$
\widetilde{w}_{i}=\tilde{r}_{i} \otimes\left(\tilde{r}_{1} \oplus \tilde{r}_{2} \oplus \ldots \oplus \tilde{r}_{n}\right)^{-1}
$$

4. Adım: Aşağıdaki eşitlik ile her bir kriterin en iyi bulanık olmayan performans değeri, Chou and Chang'ın (2008) geliştirdiği alan merkezi metodu ile elde edilir. Buna ait formül şu şekildedir:

$$
\mathrm{M}_{\mathrm{i}}=\frac{l w_{i+} m w_{i}+u w_{i}}{3}
$$


5. Adım Burada M artık bulanık olmayan bir sayıdır fakat aşağıdaki formül ile normalize edilmesi gereklidir.

$$
\mathrm{w}_{\mathrm{i}}=\frac{\mathrm{M}_{\mathrm{i}}}{\sum_{\mathrm{j}=1}^{\mathrm{n}} \mathrm{M}_{\mathrm{i}}}
$$

\section{VIKOR Metodu}

Vise Kriterijumska Optimizacija I Kompromisno Resenje (VIKOR) 2004 yllında Opricovic ve Tzeng tarafından geliştirilmiştir. VIKOR metodu uzlaşık çözümler sunmakta, bu yönüyle karar vericiler arasında fikir farklılıklarına bir çözüm getirmektedir (Opricovic ve Tzeng, 2004). Yöntemin aşamaları şu şekildedir:

\section{Adım 1:Karar Matrisinin Oluşturulması}

i alternatifleri, $\mathrm{j}$ ise kriterleri göstermek üzere, alternatiflerin kriterlere göre değerlendirilmesiyle karar matrisi (X) oluşturulur.

$$
\begin{gathered}
\mathrm{i}=(1,2, \ldots, \mathrm{m}) \\
\mathrm{j}=(1,2, \ldots, \mathrm{n}) \\
X=\left[\begin{array}{cccc}
x_{11} & x_{12} & \ldots & x_{1 n} \\
x_{21} & x_{22} & \ldots & x_{2 n} \\
\vdots & \vdots & \ddots & \vdots \\
x_{m 1} & x_{m 2} & \ldots & x_{m n}
\end{array}\right]
\end{gathered}
$$

\section{Adım 2: En iyi ve en kötü kriter değerlerinin elde edilmesi}

Her bir kriter için en iyi $f_{j}^{*}$ ve en kötü $f_{j}^{-}$değerleri kriterlerin fayda veya maliyet cinsinden olup olmadığına göre değişir. Eğer j. kriter fayda cinsinden ise;

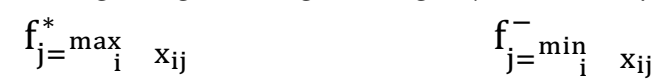

Eğer j. kriter maliyet cinsinde ise;

$$
\begin{aligned}
& f_{j=\min _{i}}^{*} x_{i j} \\
& \text { şeklinde hesaplanır. }
\end{aligned}
$$

Adım 3: $S_{i}$ ve $R_{i}$ değerlerinin elde edilmesi

$$
\begin{aligned}
& S_{i}=\sum_{j=1}^{n} w_{j}\left(f_{j}^{*}-x_{i j}\right) /\left(f_{j}^{*}-f_{j}^{-}\right) \\
& \mathrm{R}_{\mathrm{i}}=\max _{\mathrm{j}}\left[\mathrm{w}_{\mathrm{j}}\left(\mathrm{f}_{\mathrm{j}}^{*}-\mathrm{x}_{\mathrm{ij}}\right) /\left(\mathrm{f}_{\mathrm{j}}^{*}-\mathrm{f}_{\mathrm{j}}^{-}\right)\right]
\end{aligned}
$$




\section{Adım 4: $Q_{i}$ değerlerinin elde edilmesi}

$$
\begin{aligned}
S^{*} & =\min _{i} S_{i} \\
S^{-} & =\max _{i} S_{i} \\
R^{*} & =\min _{i} R_{i} \\
R^{-} & =\max _{i} R_{i} \text { olmak üzere } \\
Q_{i} & =\frac{v\left(S_{i}-S^{*}\right)}{\left(S^{-}-S^{*}\right)}+\frac{(1-v)\left(R_{i}-R^{*}\right)}{\left(R^{-}-R^{*}\right)}
\end{aligned}
$$

$\mathrm{V}$ maksimum grup faydasını gösteren strateji ağırlı̆̆ıdır. Uzlaşma durumu V>0,5 (çoğunluk oyu), $\mathrm{v}=0,5$ (konsesnsus) ile veya $\mathrm{v}<0,5$ (veto) ile sağlanabilir ( Kuzu, 2015).

\section{Adım 5: $S_{i}, R_{i}$ ve $Q_{i}$ değerlerinin sıralanması ve uzlaşık çözümün elde edilmesi}

$S_{i}, R_{i}$ ve $Q_{i}$ değerleri küçükten büyüğe sıralanır ve ardından en küçük $Q_{i}$ değerine sahip olan alternatifin aşağıdaki iki şartı sağlayıp sağlamadığı sınanır.

\section{1: Kabul Edilebilir Avantaj Şartı (C1)}

$\mathrm{m}$ alternatif sayısı iken,

$D Q=\frac{1}{m-1}$

olmak üzere, $Q_{i}$ değerleri küçükten büyüğe sıralandığında ilk sıradaki alternatif $A^{1}$ ve ikinci siradaki alternatif $\mathrm{A}^{2}$ olsun. Kabul edilebilir avantaj ise;

$Q\left(A^{2}\right)-Q\left(A^{1}\right) \geq D Q$

ile hesaplanır.

\section{2:Kabul Edilebilir İstikrar Şartı (C2)}

$\mathrm{Q}_{\mathrm{i}}$ değerleri küçükten büyüğe sıralandığında ilk sıradaki alternatif $\mathrm{A}^{1}$, $\mathrm{S}$ ve/veya $\mathrm{R}$ değerlerine göre küçükten büyüğe sıralandığında en küçük değere sahip olan alternatiftir.

Eğer şartlardan biri sağlanmıyorsa şu şekilde uzlaşılmış çözüme gidilir:

2.Şart sağlanmıyorsa $\mathrm{A}^{1}$ ve $\mathrm{A}^{2}$ seçenekleri en iyi uzlaşık çözüm olarak belirlenir.

1. şart sağlanmiyorsa tüm alternatifler en iyi çözüm kümesini oluşturur. Burada maksimum $\mathrm{M}, Q\left(A_{m}\right)-, Q\left(A^{1}\right)<D Q$ formülü ile belirlenir.

\section{Demiryolu Yük Taşımacılığı Faaliyetlerinin Değerlendirmesi}

Çalışmanın bu bölümünde ülkelere ait demiryolu yük taşımacılığı faaliyetlerinin etkinliği araştırılırken uygulanan aşamalar ele alınacaktır. 


\section{Uygulama Aşamaları}

Öncelikle demiryolu yük taşımacılığı faaliyetlerinin etkinliğinin değerlendirilmesi için kriterler belirlenmiştir. Daha sonra elde edilen kriterlere uygun veriler sağlanarak bulanık AHP yöntemiyle kriterlerin önem dereceleri (ağırlıkları) belirlenmiştir. Ağırlıkları bilinen kriterlerle ülkelerin etkinliklerinin değerlendirilip sıralanması için ise VIKOR yöntemi kullanılmıştır. Şekil 1'de uygulama aşamaları görülmektedir.

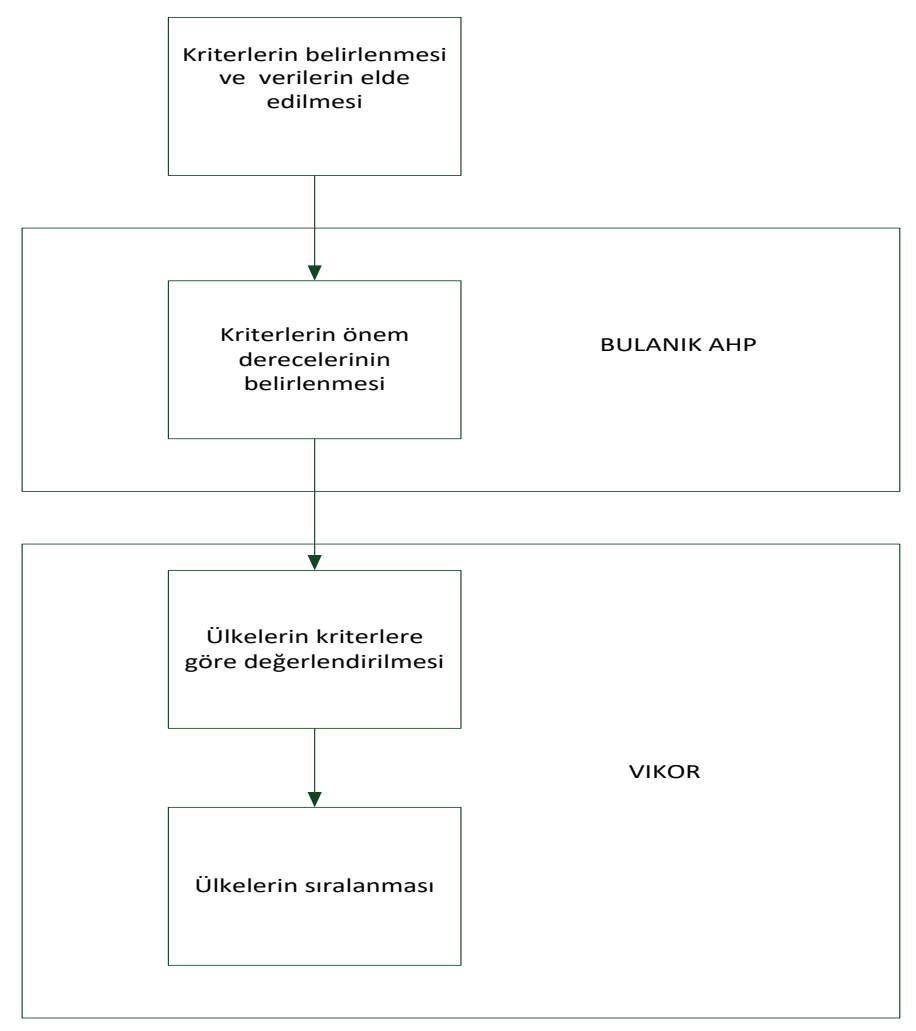

Şekil 1. Uygulama Aşamaları

\section{Aşama: Kriterlerin Belirlenmesi ve Verilerin Elde Edilmesi}

Çalışmada, literatürdeki çalışmalarda ele alınan kriterlerden de yola çıkarak, demiryolu yük taşımacılığı performansı ölçümü için derlenebilen ve gerçeği en iyi şekilde temsil edeceği düşünülen kriterlerden 5 tanesi kullanılarak ülkelerin demiryolu yük taşımacılığı performansları değerlendirilmiştir. Bu kriterler firma sayısı, hat uzunluğu (km), taşıma miktarı (ton), bakım giderleri (Euro), GSYH başına altyapı yatırımları şeklindedir.

Ülkelere ait demiryolu firması sayıları International Union of Railways (2016)'den, hat uzunluğu, taşıma miktarı, bakım giderleri ve altyapı yatırımları verileri ise OECD istatistiklerinden (2016) elde edilmiştir.

Ele alınan kriterlere ait detaylar şu şekilldedir; 
Firma Sayısı (K1): Çalışmada ele alınan ülkelerin aktif olarak faaliyet gösteren demiryolu firması sayıları International Union of Railways (2016) verilerinden elde edilmiştir.

Hat Uzunluğu (K2): Çalışmada ele alınan ülkelerin, tren servisi için mevcut olan demiryolu güzergahı uzunluğu olarak km cinsinden hat uzunluğu kriteri verileri OECD istatistiklerinden (2016) elde edilmiştir.

Taşıma Miktarı (K3): Belirli bir demiryolu ağında demiryolu aracı kullanan herhangi bir mal hareketi demiryolu taşımacılığı olarak adlandırılırken, taşıma miktarı kriteri olarak OECD istatistiklerinden (2016) elde edilen 1000 Dolarlık GSYİH'ya karşılık ton-km cinsinden demiryolu yük taşımacılığı miktarı verileri kullanılmıştır.

Bakım Giderleri (K4): Demiryolu faaliyetlerinin sürdürülebilir olması için gerekli olan bakımlarda ülkelerin Euro cinsinden harcadığı bakım giderleri verileri OECD istatistiklerinden elde edilmiştir.

Altyapı Yatırımları (K5): Ülkelerin demiryolu altyapısına yapılan yatırım harcamaları: yeniden yapılandırma, yenileme ve altyapı onarımı dahil olmak üzere yeni inşaat ve mevcut altyapının genişletilmesi için harcamalar şeklinde olup, ülkelerin GSYH'ları başına düşen oran şeklinde ele alınmış ve yine OECD istatistiklerinden elde edilmiştir.

\section{Aşama: Kriterlerin Önem Derecelerinin (Ağırlıklarının) Elde Edilmesi}

Bir önceki aşamada açıklanan kriterlerin ağırlıklarının elde edilmesi için bulanık mantık yaklaşımından faydalanılıp, bulanık AHP yöntemi kullanılmıştır. Burada; bir demiryolu ulaştırma ve taşımacılık uzmanı tarafından kriterler kendi aralarında değerlendirilmiş ve bir başlangiç matrisi elde edilmiştir. Bunu gerçekleştirirken, Tablo 1'de yer alan dilsel değişkenler ve üçgensel bulanık sayılar temel alınmıştır. Elde edilen başlangıç matrisi Tablo 2'de görülmektedir. Bulanık AHP uygulama aşamaları eşitlik (2-3) aracılığıyla gerçekleştirilerek öncelikle kriterlerin bulanık ağırlıkları elde edilmiştir. Daha sonra eşitlik (4-5) aracılığıyla kriterlerin durulaştırılmış ağırlıkları elde edilmiştir. Bunlar sırasıyla Tablo 3. ve Tablo 4'te görülmektedir. Buna göre kriterler arası ağırlık sıralaması, K3-K2-K5-K4-K1 şeklinde olup en önemli kriterin taşıma miktarı olduğuna karar verilmiştir.

Tablo 2. Başlangıç Matrisi

\begin{tabular}{|c|ccccc|}
\cline { 2 - 7 } \multicolumn{1}{c|}{} & K1 & K2 & K3 & K4 & K5 \\
\hline K1 & 1 & 0.333 & 0.333 & 0.333 & 0.2 \\
K3 & 3 & 1 & 0.2 & 5 & 3 \\
K4 & 3 & 5 & 1 & 7 & 3 \\
K5 & 3 & 0.2 & 0.143 & 1 & 0.333 \\
& 5 & 0.333 & 0.333 & 3 & 1 \\
\hline
\end{tabular}


Tablo 3. Bulanık Ağırıklar

\begin{tabular}{cccc}
\hline & I & $\mathbf{m}$ & $\mathbf{u}$ \\
\hline K1 & 0.004515 & 0.010039 & 0.028738 \\
K2 & 0.072238 & 0.172002 & 0.409827 \\
K3 & 0.302891 & 0.713117 & 1.639308 \\
K4 & 0.007861 & 0.017227 & 0.042545 \\
K5 & 0.03698 & 0.087615 & 0.235384 \\
\hline
\end{tabular}

Tablo 4. Ağırlıklar

\begin{tabular}{cc}
\hline K1 & w \\
\hline K2 & 0.173 \\
K3 & 0.702 \\
K4 & 0.017 \\
K5 & 0.095 \\
\hline
\end{tabular}

\section{Aşama: Ülkelerin Demiryolu Yük Taşımacılık Performanslarının Değerlendirilmesi}

Bir önceki aşamada kriterlerin ağırlıkları elde edilmiştir. Bu aşamada ise elde edilen bu ağırlıklar da kullanılarak VIKOR yöntemi aracılığıyla ülkelerin demiryolu yük taşımacılık performanslarının değerlendirilecektir. Ele alınan ülkeler; Türkiye (Ü1), Avusturya (Ü2), Çek Cum. (Ü3), Finlandiya (Ü4), Macaristan (Ü5), Polonya (Ü6), İsveç (Ü7) ve Slovakya (Ü8) şeklindedir. Tablo 5'te her bir ülke için International Union of Railways (2016) ve OECD istatistiklerinden (2016) elde edilen verilerin yer aldı̆̆ı başlangıç matrisi görülmektedir. Ardından eşitlik 7-11 aracılığıyla ağırlıklı standart karar matrisi ve s r q değerleri elde edilmiştir. Bunlar sırasıyla Tablo 6 ve 7'de görülmektedir. Literatürde yapılan çalışmalara uygun bir şekilde, Qi değerleri 0.1,0.5,0.75 ve 1 alınmıştır.

Tablo 5. Başlangıç Matrisi

\begin{tabular}{crrrrr}
\hline Ülkeler & K1 & K2 & K3 & K4 & K5 \\
\hline Ü1 & 1 & 10131 & 11661 & 171717474 & 0.22 \\
Ü2 & 4 & 4917 & 20856 & 535000000 & 0.431 \\
Ü3 & 2 & 9462.69 & 15619 & 576898891 & 0.386 \\
Ü4 & 2 & 5926 & 9455 & 216000000 & 0.249 \\
Ü5 & 4 & 7748.7 & 10528 & 549990368 & 0.284 \\
Ü6 & 1 & 18429 & 50650 & 729443579 & 0.077 \\
Ü7 & 3 & 9684 & 21406 & 954126308 & 0.253 \\
Ü8 & 3 & 3626.3 & 9111 & 9500000 & 0.162 \\
\hline$f j^{*}$ & 4 & 18429 & 50650 & 9500000 & 0.077 \\
$f j-$ & 1 & 3626.3 & 9111 & 954126308 & 0.431 \\
\hline
\end{tabular}


Tablo 6. Ağırlıklı Standart Karar Matrisi

\begin{tabular}{cccccc}
\hline Ülkeler & K1 & K2 & K3 & K4 & K5 \\
\hline Ü1 & 0.011 & 0.097 & 0.659 & 0.003 & 0.038 \\
Ü2 & 0.000 & 0.158 & 0.504 & 0.010 & 0.095 \\
Ü3 & 0.008 & 0.105 & 0.592 & 0.011 & 0.083 \\
Ü4 & 0.008 & 0.146 & 0.697 & 0.004 & 0.046 \\
Ü5 & 0.000 & 0.125 & 0.678 & 0.010 & 0.056 \\
Ü6 & 0.011 & 0.000 & 0.000 & 0.014 & 0.000 \\
Ü7 & 0.004 & 0.102 & 0.495 & 0.018 & 0.047 \\
Ü8 & 0.004 & 0.173 & 0.702 & 0.000 & 0.023 \\
\hline
\end{tabular}

Tablo 7. S R Q Değerleri

\begin{tabular}{|c|c|c|c|c|c|c|c|c|}
\hline Ülkeler & Si & $\mathbf{R i}$ & & & $\begin{array}{c}v=0 \\
.1\end{array}$ & $\begin{array}{c}v=0 \\
.5\end{array}$ & $\begin{array}{c}v=0 \\
75\end{array}$ & $v=1$ \\
\hline \multirow{2}{*}{ Ü1 } & 0.8 & 0.6 & $S$ & 0.0 & 0.9 & 0.9 & 0.90 & 0.8 \\
\hline & 09 & 59 & $*$ & 25 & 33 & 16 & 5 & 94 \\
\hline \multirow{2}{*}{ Ü2 } & 0.7 & 0.5 & $S$ & 0.9 & 0.7 & 0.7 & 0.81 & 0.8 \\
\hline & 67 & 04 & - & 02 & 25 & 79 & 2 & 46 \\
\hline \multirow{2}{*}{ Ü3 } & 0.7 & 0.5 & $R$ & 0.0 & 0.8 & 0.8 & 0.87 & 0.8 \\
\hline & 99 & 92 & $*$ & 14 & 44 & 61 & 2 & 82 \\
\hline \multirow{2}{*}{ Ü4 } & 0.9 & 0.6 & $R$ & 0.7 & 0.9 & 0.9 & 0.99 & 0.9 \\
\hline & 01 & 97 & - & 02 & 92 & 95 & 7 & 98 \\
\hline \multirow{2}{*}{ Ü5 } & 0.8 & 0.6 & $v$ & 0.1 & 0.9 & 0.9 & 0.96 & 0.9 \\
\hline & 69 & 78 & 1 & 00 & 65 & 64 & 3 & 62 \\
\hline \multirow{2}{*}{ Ü6 } & 0.0 & 0.0 & $v$ & 0.5 & 0.0 & 0.0 & 0.00 & 0.0 \\
\hline & 25 & 14 & 2 & 00 & 00 & 00 & 0 & 00 \\
\hline \multirow{2}{*}{ Ü7 } & 0.6 & 0.4 & $v$ & 0.7 & 0.7 & 0.7 & 0.72 & 0.7 \\
\hline & 66 & 95 & 3 & 50 & 01 & 14 & 2 & 31 \\
\hline \multirow{2}{*}{ Ü8 } & 0.9 & 0.7 & $\boldsymbol{v}$ & 1.0 & 1.0 & 1.0 & 1.00 & 1.0 \\
\hline & 02 & 02 & 4 & 00 & 00 & 00 & 0 & 00 \\
\hline
\end{tabular}

\section{Aşama: Sıralamalar ve Uzlaşık Çözümlerin Elde Edilmesi}

Bir önceki aşamada elde edilen $S_{i}, R_{i} v e Q_{i}$ değerleri Tablo 8'de görüldüğü gibi, küçükten büyüğe doğru sıralanmıştır. Uzlaşık çözüm için ise eşitlik 12 ve 13 'den faydalanarak sonuçlar elde edilmiştir ve Tablo 9'da buna dair sonuçlar görülmektedir. Elde edilen bu sonuçlara göre; Qi=0.1, 0.5 ve 1 değerleri için kabul edilebilir avantaj ve kabul edilebilir istikrar şartlarının aynı anda sağlandığı görülmektedir. Fakat Qi= 0.75 için kabul edilebilir avantaj şartı sağlandığ 1 halde, kabul edilebilir istikrar şartı sağlanamamaktadır. Sıralamalara bakıldığında Qi=0.1, 0.5 ve 1 değerleri için sıralamalar eşit olmakta bu sebeple çözüm olarak; Qi=0.1, 0.5 ve 1 değerleriyle elde edilen; Polonya- İsveç- Avusturya- Çek Cum.- Türkiye- Macaristan- Finlandiya- Slovakya

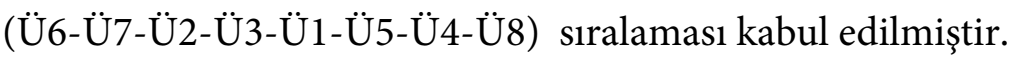


Tablo 8. $S_{i}, R_{i}$ Ve $Q_{i}$ Değerlerinin Sıralanması

\begin{tabular}{|cc|cc|cc|cc|cc|cc|}
\hline \multicolumn{2}{|c|}{ Si } & \multicolumn{2}{|c|}{$\mathbf{R i}$} & \multicolumn{2}{c|}{ Qi,v=0.1 } & \multicolumn{2}{c|}{ Qi,v=0.5 } & \multicolumn{2}{c|}{ Qi,v=0.75 } & \multicolumn{2}{c|}{ Qi,v=1 } \\
\hline Polonya & 0.025 & Polonya & 0.014 & Polonya & 0 & Polonya & 0 & Çek Cum. & 0 & Polonya & 0 \\
İsveç & 0.666 & İsveç & 0.495 & İsveç & 0.701 & İsveç & 0.714 & Macaristan & 0.722 & İsveç & 0.731 \\
Avusturya & 0.767 & Avusturya & 0.504 & Avusturya & 0.725 & Avusturya & 0.779 & İsveç & 0.812 & Avusturya & 0.846 \\
Çek Cum. & 0.799 & Çek Cum. & 0.592 & Çek Cum. & 0.844 & Çek Cum. & 0.861 & Türkiye & 0.872 & Çek Cum. & 0.882 \\
Türkiye & 0.809 & Türkiye & 0.659 & Türkiye & 0.933 & Türkiye & 0.916 & Polonya & 0.905 & Türkiye & 0.894 \\
Macaristan & 0.869 & Macaristan & 0.678 & Macaristan & 0.965 & Macaristan & 0.964 & Slovakya & 0.963 & Macaristan & 0.962 \\
Finlandiya & 0.901 & Finlandiya & 0.697 & Finlandiya & 0.992 & Finlandiya & 0.995 & Avusturya & 0.997 & Finlandiya & 0.998 \\
Slovakya & 0.902 & Slovakya & 0.702 & Slovakya & 1 & Slovakya & 1 & Finlandiya & 1 & Slovakya & 1 \\
\hline
\end{tabular}

Tablo 9. Kabul Edilebilirlik Şartlarının Değerlendirilmesi

\begin{tabular}{cccc}
\hline Qi & C1 & C2 & Sıralama \\
\hline 0.1 & DOĞRU & DOĞRU & Ü6-Ü7-Ü2-Ü3-Ü1-Ü5-Ü4-Ü8 \\
0.5 & DOĞRU & DOĞRU & Ü6-Ü7-Ü2-Ü3-Ü1-Ü5-Ü4-Ü8 \\
0.75 & DOĞRU & YANLIŞ & Ü3-Ü5-Ü7-Ü1-Ü6-Ü4-Ü8-Ü2 \\
1 & DOĞRU & DOĞRU & Ü6-Ü7-Ü2-Ü3-Ü1-Ü5-Ü4-Ü8 \\
\hline
\end{tabular}

\section{Sonuç}

Demiryolu yük taşımacılığı maliyet, güvenlik, sabit ulaştırma süreleri ve izlenebilirlik avantajlarıyla, kara, deniz ve havayolu ile taşımacılığına kıyasla oldukça elverişlidir. Bu gibi özellikleriyle demiryolu yük taşımacılığının, gelişmiş ülkelerin lojistik hizmetlerinin önemli bir parçası olduğu görülmektedir. Çevreye duyarlı, yeşilci üretim anlayışları benimseyen işletmeler demiryolu taşımacılığını diğer taşımacılık yöntemlerine tercih etmektedirler. Fakat demiryolu ulaştırma ağı kurma maliyetleri, bunun işletilmesi ve sürdürülebilirliğinin sağlanması için gerekli bakım onarım ve alt yapı maliyetleri oldukça yüksektir.

Bu çalışmada OECD üyesi 8 farklı ülke için 5 ayrı kriter üzerinden demiryolu yük taşımacılığı faaliyetlerinin etkinliği değerlendirilmiştir. Ele alınan; firma sayısı, hat uzunluğu (km), taşıma miktarı (ton), bakım giderleri (Euro), altyapı yatırımları kriterlerine ait ağırlıklar bulanık AHP yöntemi ile elde edilmiş ve ülkelere ait elde edilen gerçek verilerle bir performans sıralaması gerçekleştirmek için ise VIKOR yöntemi kullanılmıştır.

Kullanılan bulanık AHP ve VIKOR bütünleşik yöntemi, başta tedarik zinciri ve lojistik olmak üzere farklı sektörlerde uygulamalar geliştirilebilecek esnek bir yöntemdir. Çalışmadan elde edilen sonuçlara bakıldığında; kriterlerin önem dereceleri sırasıyla taşıma miktarı (K3), hat uzunluğu (K2), altyapı yatırımları (K5), bakım giderleri (K4), firma sayısı (K1) şeklinde olup, 
ülkelerin performans sıralaması Polonya- İsveç- Avusturya- Çek Cumhuriyeti- TürkiyeMacaristan- Finlandiya- Slovakya şeklinde olduğu görülmektedir.

Değerlendirmeye alına ülkeler arasında demiryolu yük taşımacılığı faaliyetlerinin en etkin olduğu Polonya, aynı zamanda en yüksek taşıma miktarına sahip ülkedir ve hat uzunluğu da en yüksek ülkedir. Bir adet firmaya sahip olmasına rağmen, demiryolu bakım giderleri açısından İsveç’ten sonra ikinci sırada yer almaktadır. Demiryolu yük taşımacılığı faaliyetlerinin en az etkin olduğu ülke Slovakya ise, aynı zamanda taşıma miktarı ve hat uzunluğu en düşük ülkedir.

Ülkemiz Türkiye, hat uzunluğu açısından Polonya'dan sonra ikinci sırada yer almakta fakat taşıma miktarı açısından dördüncü sırada yer almaktadır. Bakım giderleri açısından yedinci, altyapı yatırımları açısından ise altıncı sırada yer almaktadır. Firma sayısı ise bir adettir. $\mathrm{Bu}$ durum; hat uzunluğu ne kadar fazla olursa olsun, taşınan miktarın az olması halinde, demiryolu yük taşımacılığı faaliyetlerinin etkinliğinin, zayıf olmasına sebep olduğunu göstermektedir. Türkiye, sahip olduğu demiryolu altyapı ve kaynaklarını etkin kullanabilmek için bakım ve altyapı giderlerini artırmalı, firmaları demiryolu taşımacılığı kullanma konusunda teşvik edici politikalar geliştirmelidir.

\section{Kaynakça}

Ahi, M. T., Yıldız, K. (2017). Türkiye'de Demiryolu Sektörü İçin Lojistik Zincir Analizi ve Modellemesi - SCOR Yöntemi. TMMOB İnşaat Mühendisleri Odası 12. Ulaştırma Kongresi, 291-300.

Bojovic, N., Milenkovic, M. (2008). The Best Rail Fleet Mix Problem. Oper Res Int J., 8, 7787.

Buckley J.J. (1985). Ranking Alternatives Using Fuzzy Numbers, Fuzzy Sets Systems, 15(1), 21 31.

Cacchiani, V., Caprara, A., Toth, P. (2010). Scheduling Extra Freight Trains on Railway Networks. Transportation Research Part B., 44, 215-231.

Chang, D.Y. (1996). Applications of the Extent Analysis Method on Fuzzy AHP. Eur J Oper Res, 95, 649-55.

Chiou, Y.C., Lan, L. W., \& Yen, B. T. H. (2012). Route-based Data Envelopment Analysis Models. Transportation Research Part E: Logistics and Transportation Review, 48(2), 415425 .

Chou, S-W., and Chang, Y-C., (2008) The Implementation Factors That Influence the ERP (Enterprise Resource Planning) Benefits, Decision Support Systems, 46 (1), 149-157. 
Çekerol, G. S., Nalçakan, M. (2011). Lojistik Sektörü İçerisinde Türkiye Demiryolu Yurtiçi Yük Taşıma Talebinin Ridge Regresyonla Analizi. Marmara Üniversitesi İ.İ.B.F. Dergisi, 31(2), 321-344.

Anghinolfi, D., Paolucci, M., Sacone, S., \& Siri, S. (2011). Freight transportation in railway networks with automated terminals: A mathematical model and MIP heuristic approaches. European Journal of Operational Research, 214, 588-594.

Gürol, P. Sezer, F., Kara, K. (2015). Türkiye’de Demiryolu ile Limanlardan Taşınması Gereken Yük Miktarlarının Zaman Serisi Analiziyle Tahmin Edilmesi. Gümüşhane Üniversitesi, İktisadi ve İdari Bilimler Fakültesi IV. Ulusal Lojistik ve Tedarik Zinciri Kongresi.

Gürsoy, M. (2010). A Decision Supportive Method For Multimodal Freight Transport Mode Choice:An Example From Turkey. Iranian Journal of Science \& Technology, Transaction B: Engineering, 34, B4, 461-470.

Hajiagha1, S.H.R., Hashemi, S.S., Mohammadi, Y., Zavadskas, E.K. (2016). Fuzzy Belief Structure Based VIKOR Method: An Application For Ranking Delay Causes of Tehran Metro System By FMEA Criteria. TRANSPORT, 31(1), 108-118.

Hilmola, O.P. (2007). European railway freight transportation and adaptation to demand decline: Efficiency and partial productivity analysis from period of 1980-2003. International Journal of Productivity and Performance Management, 56(3), 205-225.

International Union of Railways Statistics. https://uic.org/statistics Erişim Tarihi: Eylül 2018.

Kuzu, S. (2015). VIKOR, Operasyonel, Yönetsel ve Stratejik Problemlerin Çözümünde Çok Kriterli Karar Verme Yöntemleri. Bursa: Dora Yayıncılık.

Liu, D. (2016). Measuring Aeronautical Service Efficiency and Commercial Service Efficiency of East Asia Airport Companies: An application of Network Data Envelopment Analysis. Journal of Air Transport Management, 52, 11-22.

Longo, G., Padoano, E., Rosato, P., Strami, S. (2009). Considerations on the Application of AHP/ANP Methodologies to Decisions Concerning a Railway Infrastructure. Proceedings of the International Symposium on the Analytic Hierarchy Process.

Nuhodzic, R., Macura, D., Bojovic, N. (2010). One Approach for Management Rail Marketing Strategies. Economic Computation \& Economic Cybernetics Studies \& Research, 44(1).

Nyström, B., Söderholm, P. (2010). Selection of Maintenance Actions Using the Analytic Hierarchy Process (AHP): Decision-Making in Railway Infrastructure. Structure and Infrastructure Engineering, 6(4), 467-479.

OECD Stats. https://stats.oecd.org/ Erişim Tarihi: Eylül 2018. 
Opricovic, S., Tzeng, G.H. (2004). Compromise solution by MCDM methods: A comparative analysis of VIKOR and TOPSIS. European Journal of Operational Research, 156, 445-455.

Ranjan, R., Chatterjee, P., Chakraborty, S. (2016). Performance Evaluation of Indian Railway Zones Using DEMATEL and VIKOR Methods. Benchmarking: An International Journal, 23(1), 78-95.

Sheth, C., Triantis, K., \& Teodorovic, D. (2007). Performance Evaluation of Bus Routes: A Provider and Passenger Perspective. Transportation Research Part E, 43, 453-478.

Tadić,S., Zečević, S., Krstić, M. (2015) Ranking of Logistics System Scenarios Using Combined Fuzzy AHP-VIKOR MODEL. International Journal for Traffic and Transport Engineering, 5(1), 54-63.

Taherkhani, H., Esfahani, M.H. (2017). Presenting a New Hybrid Model of MCDM Methods in Selecting the Best Material of Sleepers in Railway. International Journal of Railway Research, 4(1), 1-14.

Van-Laarhoven, P.J.M., Pedrycz, W. (1983). A Fuzzy Extension of Saaty's Priority Theory. Fuzzy Sets and Systems, 11, 229-241.

Vesković, S., Stević, Ž., Stojić, G., Vasiljević, M., Milinković, S. (2018). Evaluation of The Railway Management Model By Using A New Integrated Model DELPHI-SWARAMABAC. Decision-making: Applications in Management and Engineering, 1(2).

Wanke, P., Chen, Z., Liu, W., Antunesa, J.J.M., Azad, M.A.K. (2018). Investigating the drivers of railway performance: Evidence from selected Asian countries. Habitat InternationaL. $80,49-69$.

Wiegmans, B., Champagne-Gelinas, A., Duchesne,S., Slack,B. \& Witte, P. (2018). Rail and road freight transport network efficiency of Canada, member states of the EU, and the USA. Research in Transportation Business \& Management, 28, 54-65.

Yaghinia, M. \& Akhavan R. (2012). Multicommodity Network Design Problem in Rail Freight Transportation Planning. Procedia - Social and Behavioral Sciences, 43, 728 - 739.

Yang, L., Gao, Z. \& Li, K. (2011). Railway Freight Transportation Planning with Mixed Uncertainty of Randomness and Fuzziness. Applied Soft Computing, 11, 778-792.

Yu, M. M. (2008). Assessing the Technical Efficiency, Service Effectiveness, and Technical Effectiveness of the World's Railways Through NDEA Analysis. Transportation Research Part A: Policy and Practice, 42(10), 1283-1294

Yu, M.-M. \& Lin, E. T. J. (2008). Efficiency and Effectiveness in Railway Performance Using A Multi-Activity Network DEA Model. International Journal of Management Science, 36(6), 1005-1017. 
Yu, M.-M., Chen, L.-H., \& Hsiao, B. (2016). Dynamic Performance Assessment of Bus Transit with the Multi-Activity Network Structure. Omega, 60, 15-25.

Zahurul Islam, D. Md. (2018). Prospects for European Sustainable Rail Freight Transport During Economic Austerity, Benchmarking: An International Journal, 25(8), 2783-2805.

Zhang, X., Li, L. \& Zhang, J. (2019). An Optimal Service Model for Rail Freight Transportation: Pricing, Planning, and Emission Reducing. Journal of Cleaner Production, 218, 565-574. 